\title{
The castle and the isolation from the outside world
}

\begin{abstract}
The group pictogram is presented as a device-framework used on family therapy, consisting on a therapeutic mediator that brings the group's members to draw together on the same paper. The drawing produced has the power to communicate preconscious and unconscious psychic contents, similar to a dream or pictogram, and to create a dialogue among the members of the group with their drawings. A family session is described, with family members telling how the son is isolated in his own world, while living under various addictive behaviors. The Winnicotti an concept of breakdown is used then to understand the sense of emptiness and collapse, experienced by the patient in an environment without enough holding.
\end{abstract}

Keywords: group pictogram, therapeutic mediator, breakdown, addictive behaviors, family
Volume 5 Issue 2 - 2018

\author{
María Antonieta Pezo del Pino \\ University of São Paulo, Brazil
}

Correspondence: María Antonieta Pezo del Pino, PhD in Social Psychology, Institute of Social Psychology of the University of São Paulo Psychoanalyst - Professor of Rede Sampa, Member of IAGP, Brazil, Tel 005I 9986540 I2, 0055 II 997046053,Email mantonietapezo@gmail.com

Received: January 21, 2018 | Published: April 24, 2018

\section{Introduction}

In family care, among the greatest difficulties in most of the cases are the prolonged silence of one member and the long accusations against each other. Those situations generate the feeling of uselessness of the family treatment, if not desistence of some members or the whole family. We introduced the group pictogram in diagnostic sessions and therapeutic consultations with families. The group pictogram consists in the invitation - to play together - to the members of a group or a family, and to draw what they want on the same paper (size A2). The emphasis is to draw together, without specifying the content or the way they should accomplish the task. Most of the members of the families attended draw individually when invited to draw in the first meetings, and not after some resistances or objections by some ("I don't know how to draw", "I am lousy, I will not do anything well"). Few are the families that build a unique design, composed by the contributions of each one.

The group pictogram is inspired by the squiggle game, from the Winnicott therapeutic consultation, a therapeutic mediator introduced by Winnicott, ${ }^{1}$ with the purpose of opening an intimate communication with the child. The essence of the game is to use psychoanalysis as a method that prioritizes free association, floating attention, transference and interpretation. Along the cases Winnicott describes a type of work called therapeutic consultation, which unlike standard psychoanalysis, takes place in only one, two or three intense and profound encounters. Without naming it, he shows how it aligns the free associations produced in the therapy, that start to arise at the meeting and through a particular embellished dialogue, in transference and counter transference. Dialogue and communication of productions consist on: scribbles, drawings, words, stories and dreams. Associative and co-associative processes arise as they scribble, draw, comment and associate together. This intervention inspired the construction of a device-framework for the work with groups and families, denominated as a group pictogram. ${ }^{2,3}$ As Freud describes the language of dreams through pictograms or hieroglyphs - bringing unconscious, preconscious, repressed, denied or encrypted psychic contents. We would like to describe a family session.

\section{The family of Paulo}

\section{Composed of 4 members}

Father, mother and two adult children. The parents were separated 22 years ago, when the children were very young, while the eldest daughter had just left home, moving to another city due to work. The family was invited to attend some monthly sessions, while the youngest son was attended twice a week. They are invited due to their past and the risks threatening the son.

The father, a university teacher diagnosed as bipolar ten years before our consultation, regrets the late diagnosis, commenting that it came "late", when he had "finished" the relationship with his wife and left home already, after numerous violent crises. He was regularly attended by a psychotherapist, while regularly taking the medicines prescribed by his psychiatrist, and was retired due to a disability when attended the session. The housewife was recently unemployed, having suffered several beatings while living with her husband. The eldest daughter, a successful professional, left home to work in a neighboring city soon after finishing her studies, appearing to bear a great responsibility in taking care of her mother and brother. And the youngest son - whom we shall call Paulo - came to the session alone, after experiencing a paranoid crisis, and afraid of being a "bipolar" as his father.

Paulo, a 25-year-old, had a paranoid crisis described as being observed by his neighbors, who would want to kill him. He attempted suicide 3 years before, after alcohol use and disposing similar feelings. He started to work when 14 years old, as an "office boy" (popular Brazilian back-office job), and before the crisis was employed with electronic technical services. As a 19 year-old he was caught by the police with marijuana and dismissed from work, consequently decreasing his use of alcohol, marijuana and electronic games. When attended by a colleague who was alerted about his paranoid crises, he spent entire nights playing games with virtual friends, slept during the day and barely ate. As soon as he came we recommended a psychiatrist, who rapidly clarified that he did not share his father's diagnosis and medicated him. He quickly abandoned the medication 
and was approved by his sister, who commented in a family session that the medication was "absurd" and criticized the referral. He also seemed to disagree not being diagnosed as "bipolar".

In the sessions, there was usually a mutual recrimination about their family life. The father spent a long time describing his own illness and Paulo's necessary medication, while the mother complained about her son's dismissal, sleeping pattern and marijuana habits, and was tired for his lack of help. On two different occasions, when he replied to her recriminations, she got up and exited the door, saying she would never return. The daughter participated in the first meetings, moving to a distant city after 6 months.

\section{The group pictogram: the castle}

After these first sessions, given the great difficulty in talking and elaborating contents, the group pictogram was introduced, with the suggestion of drawing together. After a few words of resistance, the sister is encouraged to draw the first lines: a square with some columns taking almost entirely the whole paper and said "that's a castle". Shortly each one includes other elements to the castle, taking the form of an enclosed and isolated place, having a gate connected to a bridge, such as a medieval castle, with guards protecting from above the towers. Multiple interpretations could be done, further more as I write this paper. But what matters, as Winnicott, ${ }^{1}$ presents in the squiggle game, is to favor the establishment of a dialogue, with associations based on their own experiences as they draw.

When drawing they spoke about the missing details for a complete castle. And when I suggested to talk about this castle, the sister said: "it seems from the Middle Ages". Other associations a rised, such as "closed" or "isolated", the mother described as "protected". When the sister said that Paulo is "inside the castle", the father laughed and said "me too, I always liked castles". The mother commented that "he always laughs, finding fun in everything his son does." And Paulo added: "that's the first time we are doing something together, without fighting, we never played with my parents"..."who were constantly fighting".

We would emphasize that the castle brings the metaphor of an isolated place, protected from attacks or external violence. As if Paulo had opted for an "encapsulation" as an answer to the eminent violence that would invade him. It is remarkable to remember that as a child he experienced many scenes of domestic violence, such as his mother beaten by his father. Interestingly, at the moment of the session he lived in his room, as locked in his own world, such as the castle built by the family. He rarely left only to eat or buy cigarettes. In the session the family could meaningly bring through the castle an understanding of how they experienced Paulo's symptom, isolated in his own world in order to protect himself from his own violence.

\section{Fear of collapse}

In 1963, fear of collapse is described by Winnicott, ${ }^{1}$ as a situation early experienced from environmental failure and deprivation, when the self is not yet integrated, describing a defensive organization before and unthinkable experience, given that no record or representation is possible, having happened before the integration of the self. In the neuroses Freud describes the anguish of castration as a defense, already in psychotic states the failure in the integration of the self is prioritized. This is not a traumatic situation that could be remembered, even after some period, with some difficulty or not. What Winnicott, ${ }^{1}$ describes is the existence of a "non-experience", since the event is not "remembered", but even harder, when "something not happening while something positive could have happened, creating the feeling of emptiness". ${ }^{1}$

The fear of collapse is not something that can be verbalized as "I'm afraid of a dog" or "afraid of facing life", but a sensation and defense articulating the imminence of falling at any moment, without the support of a gaze - a maternal function. The collapse, Winnicott asserts, would have been happened and kept without registration or representation, only as an unspeakable anguish. Such anguish could arise when similar failures occur in the subject's life. We think that particular experiences such as family violence, exile, immigration or emigration, lack of maternal or child care could favor the emergence of these experiences.

\section{The addictive conduct}

We highlighted how Paulo lives in his own world, isolated from outside contact, as if closeness and affectivity could endanger his survival. The medieval castle designed shows how each member of the family was looking for ways to protect themselves against the violence generated by their differences. The protections around the castle indicate how the outside world is experienced as dangerous, capable of destabilizing and creating a crisis. The challenges of growing up in the outside world, with its professional and affective requirements, seem to present a great danger. Paulo, locked in his own world, seems to protect himself from the eminent dangers, which could further destabilize his already fragile constitution.

The sense of emptiness, feelings of loneliness and lack of protection provided by his parenting figures, all described throughout the sessions, seem to have been following him through life. He remembers a mother who constantly demanded and criticized him, considered him a "copy of his father" as he grew up and was frightened that he could be a "bipolar". While living together with his children, the father had almost no closeness with them. After the divorce, he started to see them every fortnight, being a figure who could not take care of them. On one occasion, when Paulo was four years-old, he was run over in front of his father's house due to his lack of care. This happened again when he was eight years-old, under his maternal grandmother's watch, while his mother was working.

The care, warmth and protection seem not to have existed in Paulo's early life, in contrast to experiences of break and lack of support. The sensation of collapse described by Winnicott, ${ }^{1}$ is quite significant, as if there had been an environmental failure when something positive could have happened. The emptiness seemed to be hamper any possibility of feeling whole and integrated. His addictions as a young man served to fill the feelings of emptiness earlier experienced.

\section{Final considerations}

a. The group pictogram is presented as a therapeutic mediator, a useful device in the first meetings with a group or family, in therapeutic consultations or specific moments of the therapeutic process, especially when the possibilities of elaborating and dialoguing are interrupted or prevented due to the accumulated tension. In situations of crisis and violence, when speech is blocked due to the impossibility of naming the experienced. ${ }^{4}$ 
b. When experiences of violence are found inside the family.

c. Addictive behaviors appear to be ways of filling the sensation of emptiness produced by the lack of an appropriate envirornment.

\section{Acknowledgements}

None.

\section{Conflict of interest}

The authors declare there is no conflict of interest.

\section{References}

1. Winnicott Clare, Shepherd R. Psychoanalytic Explorations of D.W. Winnicott. J American Psycho Associ. 1994;42(1):268-271.

2. Pezo MAP. The group pictogram with families in crisis situation. Buenos Aires, Argentina, III Congreso de Configuraciones vinculares: 2012.

3. Pezo MAP. From the squiggle of the therapeutic consultation to the collective drawing in the institutional intervention. Digital Library. 2009. $201 \mathrm{p}$.

4. Pezo MAP. The group associative chain and the group pictogram (PhD's thesis). Brazil: 2014. 